\title{
ANALYTICAL METHOD OPTIMIZATION AND VALIDATION OF GLIBENCLAMIDE AND METFORMIN HYDROCHLORIDE IN DIABETIC HERBS PRODUCT BY THIN-LAYER CHROMATOGRAPHY-DENSITOMETRY
}

\author{
BAITHA PALANGGATAN MAGGADANI*, NOVIANI SUGIANTO, HAYUN
}

Faculty of Pharmacy, Universitas Indonesia, Depok, Indonesia. Email: baitha.p@farmasi.ui.ac.id

Received: 02 October 2019, Revised and Accepted: 24 December 2019

\section{ABSTRACT}

Objective: This study aimed to develop and validate an analytical method using thin-layer chromatography (TLC)-densitometry for detecting the presence of glibenclamide and metformin hydrochloride in herbal diabetic products.

Methods: The jamu samples were extracted using methanol, followed by analysis using TLC-densitometry with methanol-aquades-glacial acetic acid (9:1:0.25) as the mobile phase at a wavelength of $237 \mathrm{~nm}$.

Results: From the validation results, the correlation coefficients for glibenclamide and metformin hydrochloride were determined to be 0.9998 and 0.9981 , respectively. The limits of detection and quantitation for glibenclamide were $49.97 \mu \mathrm{g} / \mathrm{mL}$ and $66.55 \mu \mathrm{g} / \mathrm{mL}$, respectively, while those of metformin hydrochloride were $74.75 \mu \mathrm{g} / \mathrm{mL}$ and $249.25 \mu \mathrm{g} / \mathrm{mL}$, respectively. The method developed in this study met the criteria of selectivity, accuracy, and precision. From seven jamu samples tested, four tested positive for glibenclamide, with sample $1=4.9522 \%$, sample $2=4.1495 \%$, sample $3=4.2578 \%$, and sample $4=4.9412 \%$.

Conclusion: None of the jamu samples contained metformin hydrochloride.

Keywords: Glibenclamide, Metformin hydrochloride, Optimization, Thin-layer chromatography densitometry, Validation.

(c) 2020 The Authors. Published by Innovare Academic Sciences Pvt Ltd. This is an open access article under the CC BY license (http://creativecommons. org/licenses/by/4. 0/) DOI: http://dx.doi.org/10.22159/ijap.2020.v12s1.FF014

\section{INTRODUCTION}

Traditional medicine has been widely used by Indonesian people since ancient times. It can be used in the treatment of diseases, as well as part of an overall strategy for disease prevention and health optimization. Traditional medicines are substances or formulas of substances in the form of herbal mixes, animal compounds, minerals, essence preparations (galenic), or a mixture thereof, and have been used from generation to generation for treatments based on experience [1]. The use of traditional medicine is generally preferred over that of synthetic drugs, also known as modern medicine. The side effects of traditional medicines are considered fewer than in those of modern medicine such that traditional medicine is said to be safer than modern medicine [2]. However, in Indonesia, many traditional medicines have been found to contain medicinal chemicals that are harmful to human health.

In November 2015, the BPOM announced 50 traditional medicines and food supplements that were considered harmful because they contained medicinal chemicals. The medicinal chemicals that have been found in traditional medicines and food supplements include paracetamol, caffeine, tadalafil, and sildenafil citrate [1]. However, according to the Republic of Indonesia Indonesian Minister of Health Regulation No. 007 (2012) concerning the Registration of Traditional Medicines, traditional medicines are prohibited to contain medicinal chemicals, which are the result of isolation or synthetic preparation and have medicinal properties [3].

One example of a traditional medicine commonly consumed by Indonesian people is jamu. Several studies have reported the discovery of medicinal chemicals in herbal medicines, including the addition of corticosteroid hormones in jamu for aching pain [4]. In addition, using thin-layer chromatography (TLC)-densitometry, mefenamic acid, paracetamol, and ibuprofen have been found to be present in jamu formulations used for gout [5]. Accordingly, many herbal formulations that have not been studied remain, including jamu for diabetes. While a medicinal chemical analysis was performed on jamu for diabetes by Jayanti et al. in 2015, the method was only performed qualitatively [6].

Therefore, the development of an analytical method for determining the presence of chemical drugs in jamu for diabetes by TLC-densitometry, both qualitatively and quantitatively, is needed. In addition, it is important to determine the limits of detection (LOD) of chemical drugs in jamu samples. It is expected that the LOD of analytes in jamu samples may give better results than those found in the previous studies. This study was also conducted to determine if there are dangerous levels of medicinal chemicals present in jamu samples. The compounds we analyzed for were glibenclamide and metformin hydrochloride, which are common drugs used in the treatment of diabetes. TLC-densitometry was chosen as the best method because it uses simple equipment, the mobile phase is relatively inexpensive, and it can quickly analyze for compounds in jamu.

\section{METHODS}

The materials used were the drugs glibenclamide (PT. Indofarma Tbk, Indonesia) and metformin hydrochloride (PT. Dexa Medica Tbk, Indonesia); chemicals in the form of aquades (Merck, Germany), methanol p.a (Merck), toluene p.a (Merck), glacial acetic acid p.a (Merck), ammonia 25\% p.a (Merck), and ethyl acetate p.a (Merck). The samples analyzed were seven samples of jamu for diabetes, consisting of three samples of branded jamu (samples MX, CR, and NE) and four samples of concoction jamu (samples BI, SU, SP, and LN), which were obtained from the stores in Tangerang, Indonesia.

The spots obtained after TLC were analyzed using densitometer (Camag TLC Scanner 3), a computer connected to a scanner and equipped with "Wincats" applications, chamber chromatography, sonicators, TLC Silica gel $60 \mathrm{~F}_{254}$ plates, UV Cabinet, volume pipettes, capillary pipes, Whatman ${ }^{\circledR}$ grade 41 filter paper, and glassware. 
Preparation of standard solution

To prepare the glibenclamide standard solution, a total of $10 \mathrm{mg}$ of glibenclamide was weighed and placed into a $10 \mathrm{~mL}$ volumetric flask; methanol was then added to the volume limit to obtain a standard solution concentration of $1 \mathrm{mg} / \mathrm{mL}(1000 \mu \mathrm{g} / \mathrm{mL})$. Similarly, to prepare the metformin hydrochloride standard solution, a total of $10 \mathrm{mg}$ metformin hydrochloride was weighed and placed into a $10 \mathrm{~mL}$ volumetric flask; methanol was then added to the volume limit to obtain a standard solution concentration of $1 \mathrm{mg} / \mathrm{mL}(1000 \mu \mathrm{g} / \mathrm{mL})$.

\section{Preparation of sample solution}

A single dose sample of each herbal formulation was weighed and placed into a mortar and crushed until homogeneous. A total of $350 \mathrm{mg}$ (or equal to $1 / 20$ of the jamu weight) was weighed carefully and placed into a $10 \mathrm{~mL}$ volumetric flask; methanol was then added to represent half of the solvent. The mixture was then shaken until homogeneous, sonicated until dissolved, and methanol added to the volume limit.

Preparation of sample solutions that adduct with drug compounds A single dose sample for each herbal formulation was weighed and placed into a mortar and crushed until homogeneous. A total of $350 \mathrm{mg}$ (or equal to $1 / 20$ of the jamu weight) was weighed carefully and placed into a $10 \mathrm{~mL}$ volumetric flask; methanol was then added to represent half of the solvent. The mixture was then shaken until homogeneous and sonicated until dissolved. Two milliliters each of the standard solutions of glibenclamide $(1000 \mu \mathrm{g} / \mathrm{mL})$ and metformin hydrochloride $(1000 \mu \mathrm{g} / \mathrm{mL})$ were then added to sufficient volume.

\section{Mobile phase selection}

This experiment was conducted using $2 \mu \mathrm{L}$ glibenclamide and metformin hydrochloride standard solutions on the TLC plate, followed by elution with the mobile phase that had been used in the previous studies with an elution limit of up to $9 \mathrm{~cm}$. A mobile phase that could separate the four compounds well and had a retention factor (Rf) range of $0.2-0.8$ (Table 1 ) was chosen.

\section{Optimum wavelength optimization}

From the solution made for mobile phase optimization, repeated analysis using densitometry at the wavelength of each drug compound based on the literature was performed $[7,8]$. The optimal wavelength that could analyze each compound by providing the largest area (Table 2) was selected.

\section{Extraction system optimization}

A total of $350 \mathrm{mg}$ (or equal to $1 / 20$ of the jamu kosong weight) was weighed carefully and placed into a $10 \mathrm{~mL}$ volumetric flask; approximately $2.0 \mathrm{~mL}$ of glibenclamide solution was added to sufficient volume. The same procedure was performed with the metformin hydrochloride solution. To separate the insoluble particles, filtration and precipitation were performed for $5 \mathrm{~min}$. Then, the filtrate, supernatant, and standard solution were dropped on one TLC plate and

\section{Table 1: Mobile phase selection}

\begin{tabular}{ll}
\hline No. & Mobile phase \\
\hline 1. & Ethyl acetate-methanol-ammonia $25 \%(80: 15: 5)$ \\
2. & Methanol-ammonia $25 \%(100: 1.5)$ \\
3. & Toluene-ethyl acetate-methanol $(7.5: 0.5: 2)$ \\
4. & Aquades-methanol-glacial acetic acid $(6: 4: 0.25)$ \\
5. & Aquades-methanol-glacial acetic acid $(7: 3: 0.25)$ \\
6. & Aquades-methanol-glacial acetic acid $(8: 2: 0.25)$ \\
7. & Aquades-methanol-glacial acetic acid $(9: 1: 0.25)$ \\
\hline
\end{tabular}

Table 2: Wavelengths of each substance based on the literature

\begin{tabular}{ll}
\hline Medicinal compound & Wavelength \\
\hline Glibenclamide & $257 \mathrm{~nm}, 300 \mathrm{~nm}$ \\
Metformin hydrochloride & $237 \mathrm{~nm}, 256 \mathrm{~nm}$ \\
\hline
\end{tabular}

eluted with the selected mobile phase. A separation method that would provide a larger area of the analysis results and closest to the standard area was chosen.

\section{Method validation}

Specificity and selectivity

Specificity and selectivity tests were performed by comparing the results of the analyses of the jamu solutions that did not contain medicinal chemicals, the jamu solution that drug compounds were added, and standard solutions. The method was considered selective, if there was no spotting for the jamu solution that did not contain the medicinal chemicals at the Rf for each standard solution and the adducted jamu solution.

\section{Linearity and calibration curves}

A total of $250 \mathrm{mg}$ standard glibenclamide was weighed and placed into a $25 \mathrm{~mL}$ volumetric flask; a sufficient volume of methanol was then added to mark the boundary so that a standard solution concentration of $10,000 \mu \mathrm{g} / \mathrm{mL}$ was obtained. Aliquots of the solution were pipetted sequentially at $0.5,1,1.5,2,2.5$, and $3 \mathrm{~mL}$ into a $10 \mathrm{~mL}$ volumetric flask; a sufficient volume of methanol was then added to mark the boundary so that concentrations of $500 \mu \mathrm{g} / \mathrm{mL}, 1000 \mathrm{mg} / \mathrm{mL}, 1500 \mathrm{mg} / \mathrm{mL}$, $2000 \mathrm{mg} / \mathrm{mL}, 2500 \mathrm{mg} / \mathrm{mL}$, and $3000 \mathrm{mg} / \mathrm{mL}$ were obtained.

A total of $100 \mathrm{mg}$ standard metformin hydrochloride was weighed and placed into a $50 \mathrm{~mL}$ volumetric flask; a sufficient volume of methanol was then added to mark the boundary so that a standard solution concentration of $2000 \mu \mathrm{g} / \mathrm{mL}$ was obtained. Aliquots of the solution were pipetted sequentially at $3,4,5,6,7$, and $8 \mathrm{~mL}$ into a $10 \mathrm{~mL}$ volumetric flask; a sufficient volume of methanol was then added to mark the boundary so that concentrations of $600 \mu \mathrm{g} / \mathrm{mL}, 800 \mu \mathrm{g} / \mathrm{mL}, 1000$ $\mu \mathrm{g} / \mathrm{mL}, 1200 \mu \mathrm{g} / \mathrm{mL}, 1400 \mu \mathrm{g} / \mathrm{mL}$, and $1600 \mu \mathrm{g} / \mathrm{mL}$ were obtained.

Each solution was then dropped as much as $2 \mu \mathrm{L}$ onto the TLC plate and analyzed.

\section{LOD and limit of quantitation (LOQ)}

From the calibration curve data, the LOD and LOQ were calculated. LOD and LOQ values were calculated by measuring the replicates of the blank sample and calculating the mean result and the standard deviation.

\section{Accuracy and precision}

Accuracy and precision tests were performed by diluting the standard solution of glibenclamide $(10,000 \mu \mathrm{g} / \mathrm{mL})$ and metformin hydrochloride $(2000 \mu \mathrm{g} / \mathrm{mL})$ to obtain solutions of three different concentrations.

Accuracy and precision tests for the standard solution of glibenclamide were performed at concentrations of $3500 \mu \mathrm{g} / \mathrm{mL}, 2000 \mu \mathrm{g} / \mathrm{mL}$, and $500 \mu \mathrm{g} / \mathrm{mL}$. For the standard solution of metformin hydrochloride, accuracy and precision tests were performed at concentrations of $1600 \mu \mathrm{g} / \mathrm{mL}, 1200 \mu \mathrm{g} / \mathrm{mL}$, and $600 \mu \mathrm{g} / \mathrm{mL}$. Each solution was put into a total of $350 \mathrm{mg}$ (or equal to $1 / 20$ the dosage) of the blank matrix that did not contain any medicinal ingredients and then dropped onto the TLC plate as much as six drops. The mixture was then eluted with the selected mobile phase. We calculated the percent recovery by entering the area data obtained from the TLC-densitometry analysis. Standard deviation values and the coefficient of variation were calculated from data obtained from the accuracy analysis.

\section{Qualitative analysis of medicinal compounds in jamu}

A total of $350 \mathrm{mg}$ of the jamu sample were weighed and placed into a $10 \mathrm{~mL}$ volumetric flask and then dissolved in $5 \mathrm{~mL}$ of methanol with sufficient volume to mark the boundary. Two microliters of this solution were then dropped onto the TLC plate using capillary pipettes. The standard solution and the adducted jamu solution were also dropped as much as $2 \mu \mathrm{L}$ onto the same TLC plate and eluted with the selected mobile phase, followed by TLC-densitometry analysis. From the positive results of the qualitative analysis of the jamu solution containing the chemical compounds, quantitative analysis was performed. 
Quantitative analysis of medicinal compounds in jamu

From the samples that had a positive result in qualitative testing, quantitative tests were performed by weighing $350 \mathrm{mg}$ of the jamu sample that was detected to contain added medicinal chemicals qualitatively 2 times; this was then placed into a $10 \mathrm{~mL}$ volumetric flask with a sufficient volume of methanol to mark the boundary.

\section{RESULTS AND DISCUSSION}

\section{Mobile phase selection}

To determine the optimal conditions for analysis, the selection of the best mobile phase for the analysis of glibenclamide and metformin hydrochloride was performed. From the experimental results, it was found that the mobile phase used to optimally separate glibenclamide and metformin hydrochloride was methanol-aquades-glacial acetic acid (9:1:0.25) with an Rf of 0.82 for glibenclamide and an Rf of 0.49 for metformin hydrochloride (Fig. 1).

\section{Optimum wavelength determination}

From the experimental results, the optimum wavelength that was used for the glibenclamide and metformin hydrochloride analysis was $237 \mathrm{~nm}$, which obtained the largest area of the two compounds (Table 3).

\section{Extraction system optimization}

Extraction optimization was performed by comparing the area of the jamu adducts solution with the glibenclamide, and metformin hydrochloride filtered with filter paper and precipitated for $5 \mathrm{~min}$. The best extraction optimization used consisted of precipitation for $5 \mathrm{~min}$ because an area larger than the filtered area was obtained (Table 4).

\section{Method validation}

Selectivity

For testing the selectivity, the standard solution, jamu kosong solution, and adducted jamu solution were spotted. The results showed that

Table 3: Optimum wavelength determination results

\begin{tabular}{lll}
\hline Wavelength (nm) & Area (AU) \\
\cline { 2 - 3 } & Glibenclamide & Metformin hydrochloride \\
\hline 237 & 10921.0 & 19757.0 \\
254 & 8424.8 & 15300.9 \\
256 & 7584.6 & 13244.4 \\
257 & 7032.1 & 10501.9 \\
300 & - & - \\
\hline
\end{tabular}

Table 4: Results of the extraction system selection

\begin{tabular}{lll}
\hline Extraction & Area (AU) \\
\cline { 2 - 3 } & Glibenclamide & Metformin hydrochloride \\
\hline Standard & 7909.5 & 8845.5 \\
Filtration & 5472.0 & 5794.1 \\
Precipitation & 8931.8 & 6091.6 \\
\hline
\end{tabular}

Table 5: Accuracy and precision test results

\begin{tabular}{llll}
\hline $\begin{array}{l}\text { Medicinal } \\
\text { compounds }\end{array}$ & Concentration $(\boldsymbol{\mu g})$ & Recovery $(\%)$ & \% CV \\
\hline Glibenclamide & 1.006 & 98.46 & 1.059 \\
& 4.024 & 99.15 & 1.506 \\
& 7.042 & 100.18 & 2.087 \\
Metformin & 1.2168 & 99.89 & 1.163 \\
hydrochloride & & & \\
& 2.4336 & 100.71 & 2.187 \\
& 3.2248 & 100.81 & 1.204 \\
\hline
\end{tabular}

CV: Coefficient of variation this method was selective because there was no interference from the matrix in the Rf of glibenclamide and the Rf of metformin hydrochloride.

\section{Linearity and calibration curves}

From the results of spotting the standard glibenclamide solution at concentrations of $500 \mu \mathrm{g} / \mathrm{mL}, 1000 \mu \mathrm{g} / \mathrm{mL}, 1500 \mu \mathrm{g} / \mathrm{mL}$, $2000 \mu \mathrm{g} / \mathrm{mL}, 2500 \mu \mathrm{g} / \mathrm{mL}$, and $3500 \mu \mathrm{g} / \mathrm{mL}$ and the standard metformin hydrochloride solution at concentrations of $600 \mu \mathrm{g} / \mathrm{mL}, 800 \mu \mathrm{g} / \mathrm{mL}$, $1000 \mu \mathrm{g} / \mathrm{mL}, 1200 \mu \mathrm{g} / \mathrm{mL}, 1400 \mu \mathrm{g} / \mathrm{mL}$, and $1600 \mu \mathrm{g} / \mathrm{mL}$, the method revealed a linear relationship. The glibenclamide calibration curve resulted in a correlation coefficient value of 0.9998 , and the metformin hydrochloride calibration curve resulted in a correlation coefficient value of 0.9981 (Figs. 2 and 3).

The r-value for glibenclamide meets the specified linearity criteria of being $>0.999$ [9]. However, the $r$-value for metformin hydrochloride did not meet this standard. This may be due to errors in standard dilution,

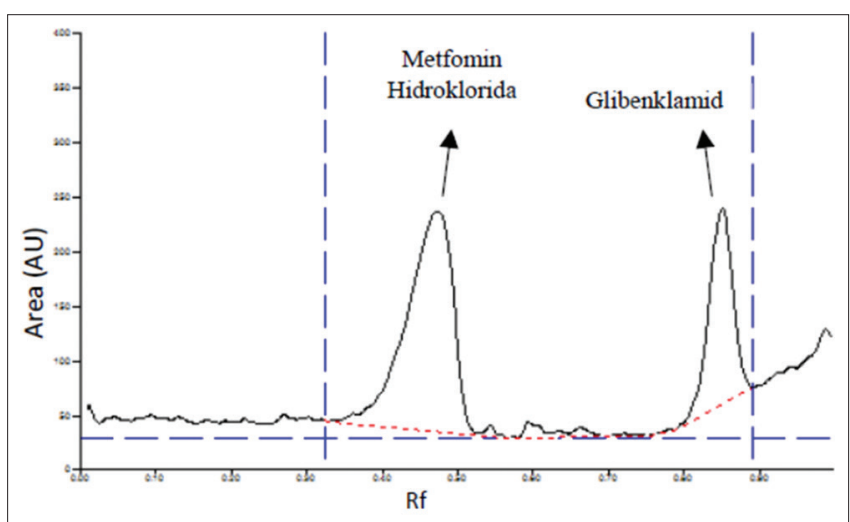

Fig. 1: Chromatogram of the glibenclamide and metformin hydrochloride compounds

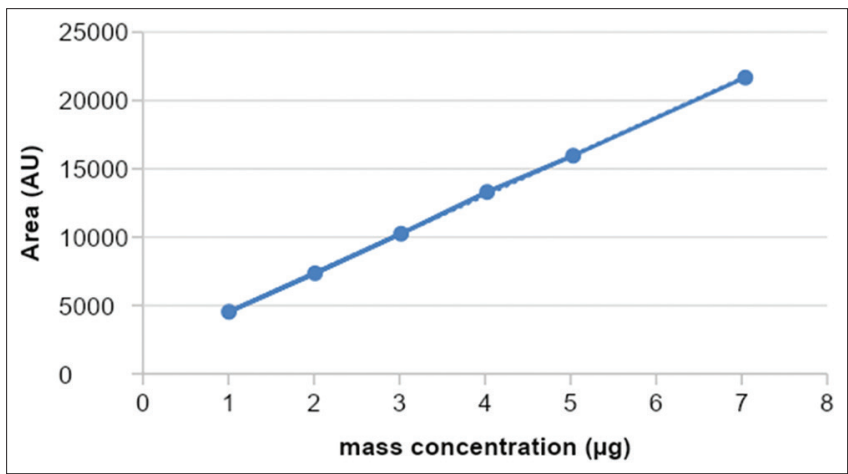

Fig. 2: Glibenclamide calibration curve

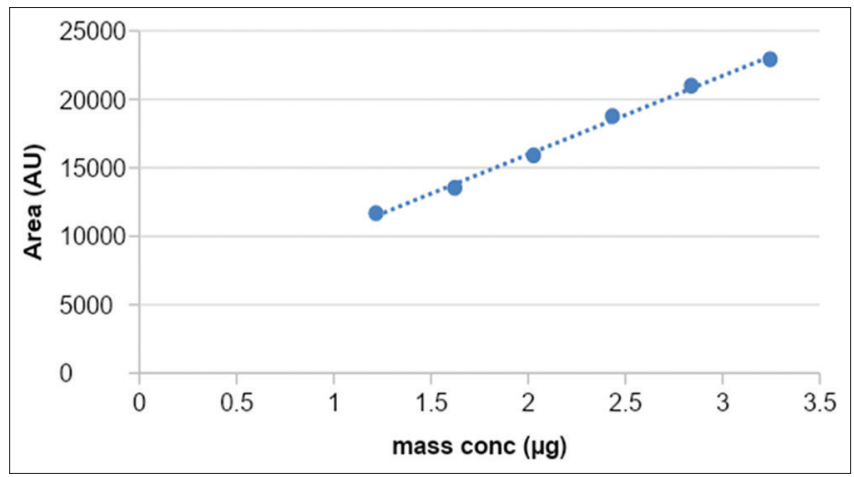

Fig. 3: Metformin hydrochloride calibration curve 
Table 6: Quantitative sample test results

\begin{tabular}{lllll}
\hline Jamu for diabetes & Levels $(\boldsymbol{\mu g} / \mathbf{m L})$ & Content $(\%)$ & Average content $(\%)$ & Weight of drug in sample packs (mg) \\
\hline BI sample & 1668.19 & 4.7602 & 4.9522 & 17.3327 \\
& 1801.62 & 5.1442 & & \\
SU sample & 1454.11 & 4.1389 & 4.1495 & \\
& 1461,56 & 4.1601 & & 14.9055 \\
SP sample & 1503.08 & 4.2699 & 4.2587 & 17.2942 \\
LN sample & 1493.85 & 4.2475 & & \\
& 1765.03 & 5.0028 & 4.9412 & \\
\hline
\end{tabular}
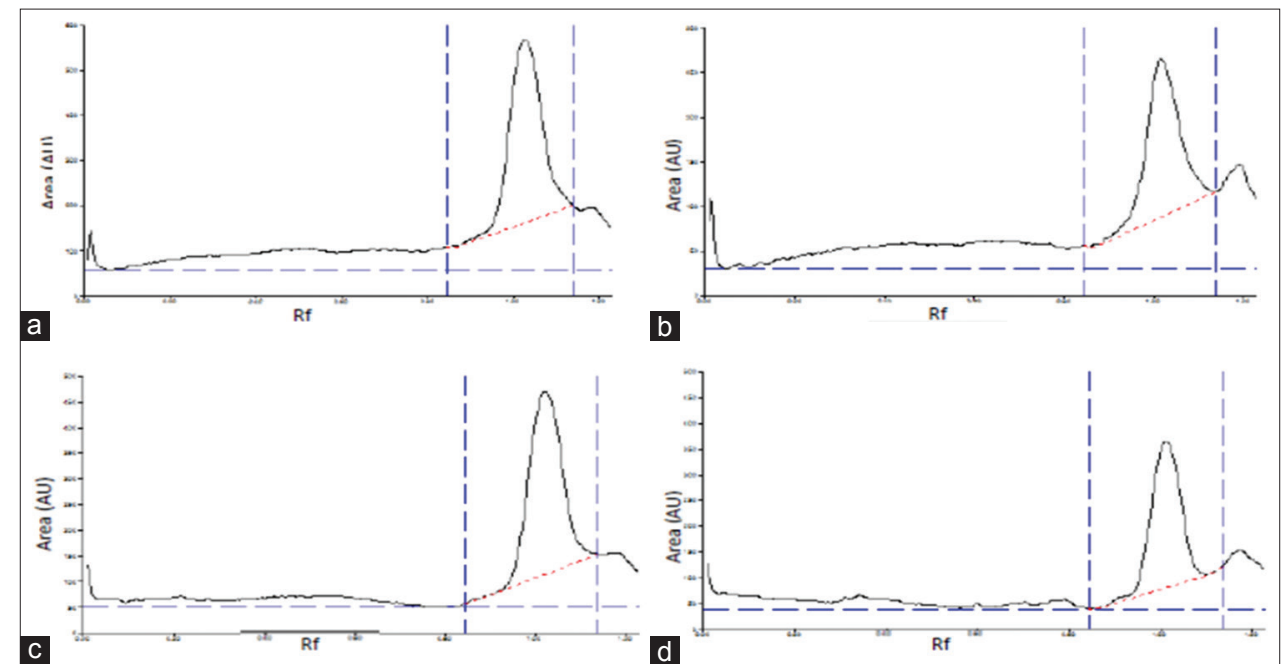

Fig. 4: Chromatograms of the jamu samples analyzed. (a) B1 sample; (b) SU sample; (c) SP sample; and (d) LN sample

errors when spotting the sample, and/or the influence of the particular instruments used. Nonetheless, the results are still considered acceptable in terms of linearity. According to Krausse (2003), the $r$-value of the linearity requirement is $r \geq 0.98$. As such, to obtain better linearity results, an experiment can be repeated [10].

\section{LOD and LOQ}

From the results of the LOD and LOQ tests, the LOD and LOQ values for glibenclamide were $49.97 \mu \mathrm{g} / \mathrm{mL}$ and $166.55 \mu \mathrm{g} / \mathrm{mL}$, respectively. The LOD and LOQ values for metformin hydrochloride were $74.75 \mu \mathrm{g} / \mathrm{mL}$ and $249.25 \mu \mathrm{g} / \mathrm{mL}$, respectively.

\section{Accuracy and precision}

From the results of the three concentrations (low, medium, and high) with six spottings, the average recovery value (Table 5) was obtained. The method we used met the accuracy requirements in terms of the recovery values being in the range of $98-102 \%$. In addition, the method showed good precision, with correlation coefficient values below 2\% [9] for glibenclamide compounds at low and moderate concentrations and for metformin hydrochloride compounds at low and high concentrations. Poor precision, as indicated by correlation coefficient values of more than $2 \%$, maybe caused by errors when spotting the sample so that inaccurate analysis results are obtained. Moreover, there may also be an influence on the equipment or laboratory conditions. According to Riyanto (2014), variations in precision results can be due to random errors, such as the instability of instruments, variations in temperature or reagents used, and the diversity of techniques and different operators. To reduce these errors, an experiment can be repeated [11-13].

\section{Qualitative analysis of samples}

From the seven analyzed samples, four samples were positive for containing glibenclamide, namely, the BI, SU, SP, and LN samples; but there was no metformin hydrochloride found in any of the tested samples. This can be seen from the Rf value and its absorption compared with the standard and adducted samples. The resulting $\mathrm{Rf}$ value is close to the same as the Rf standard of glibenclamide (Fig. 4).

\section{Quantitative analysis of samples}

From the results obtained, glibenclamide levels in the samples exceeded the LOQ. At these levels, the added glibenclamide would be expected to provide an increased antidiabetic effect within the jamu formulation. In addition, the amount of glibenclamide found in the jamu BI and jamu LN samples was equivalent to 3.5 times the usual dosage, while that found in the jamu SU and jamu SP samples was equivalent to 2.9 times the usual dose, where the value of the usual dose of glibenclamide is $5 \mathrm{mg}$. It can be concluded that these jamu formulations are very dangerous for the treatment of diabetes because they contain medicinal chemicals in the form of glibenclamide greater than the standard dosage (Table 6).

\section{CONCLUSION}

The selected mobile phase used for this study was methanol-aquadesglacial acetic acid (9:1:0.25) with an Rf value of 0.82 for glibenclamide and an $\mathrm{Rf}$ value of 0.49 for metformin hydrochloride. The best extraction system was obtained by precipitating the jamu for $5 \mathrm{~min}$. The optimum wavelength for the analysis was $237 \mathrm{~nm}$. Our validation results indicated that this method meets the requirements of linearity, selectivity, accuracy, and precision based on predetermined criteria.

From the seven jamu samples for diabetes, four contained glibenclamide, and none contained metformin hydrochloride. The content of glibenclamide in the samples was $4.9522 \%$ in the BI sample, $4.1495 \%$ in the SU sample, $4.2587 \%$ in the SP sample, and $4.9412 \%$ in the LN sample.

Action needs to be taken by the government to monitor the misuse of the addition of BKO to the herbal medicines available in the market. This is a matter of concern for health practitioners; the government should educate consumers and sellers about the dangers of products 
in circulation. Stricter supervision of traditional medicine distribution needs to be done to tackle the circulation of dangerous products in the community.

\section{ACKNOWLEDGMENTS}

The authors would like to thank head, staff, and lecturers of the Faculty of Pharmacy, Universitas Indonesia, for their support during this research.

\section{CONFLICTS OF INTEREST}

The authors declare that they have no conflicts of interest.

\section{REFERENCES}

1. The Ministry of Health. Farmakope Herbal Indonesia. $2^{\text {nd }}$ ed. Indonesia: The Ministry of Health; 2017.

2. Sari LO. Utilization of traditional medicine with consideration of the benefits and safety pemanfaatan obat tradisional dengan pertimbangan manfaat dan keamanannya. Majalah Ilmu Kefarmasian 2006;3:1-7.

3. Ministry of Health, Republic of Indonesia. Regulation Number 007 in 2012 Concerning Registration of Traditional Medicine. Indonesia: Ministry of Health Republic of Indonesia; 2012.

4. Syaripudin M. Analysis of Corticosteroid in Aching Aches Analisis Kortikosteroid Dalam Jamu Pegal Linu. Depok: Faculty of Mathematics and Sciences of Universitas Indonesia; 1997.

5. Adriyani Y. Optimization and Validation of Piroxicam, Prednisone, and
Naproxen Analysis Methods in Gout Herbs by TLC-densitometry and their Application in Several Samples. Depok: Faculty of Pharmacy of Universitas Indonesia; 2013.

6. Jayanti R, Aprilia H, Lukmayani Y. Qualitative Analysis of Glibenclamide Checmical Drugs in Diabetes Herbal Preparations on the Market. Indonesia: Prosiding Penelitian SPeSIA Unisba; 2015. p. 649-53

7. Gabhe S, Mahadik K, Potawale S, Thati A. Development and Validation of Chromatographic Methods for Simultaneous Quantification of Drugs in Bulk and in their Formulations. Hamburg: Anchor Academic Publishing; 2015.

8. Moffat AC, Osselton MD, Widdop B. Clarke's Analysis of Drugs and Poisons. London: Pharmaceutical Press; 2007.

9. Harmita. Physicochemical Analysis. Depok: Department of Pharmacy, Faculty of Mathematics and Science Universitas Indonesia; 2006.

10. Krausse OS. Good Analytical Method Validation Practice Deriving Acceptance Criteria for the AMV Protocol. Part II. Germany: Bayer Health Care Coorporation; 2003. p. 31-47.

11. Riyanto. Validation and Verification of Test Methods: In Accordance with ISO/IEC 17025 Testing and Calibration Laboratories. Yogyakarta: Penerbit Deepublish; 2014

12. Bouchaib I, Mohamed S, El Mestafa EH, Sanae A, Taoufiq S. A statistical approach based on the total error concept for validation the bioanalytical method: Application to the spectrophotometric determination of traces amount of acetaminophen in human plasma. Int J Pharm Pharm Sci 2014;6:413-21.

13. Ravichandran V, Shalini S, Sundram KM, Rajak H. Validation of analytical methods-strategies and importance. Int J Pharm Pharm Sci 2010;2:18-22. 